\title{
Feeling 'Pushed' but 'Clinging on': Juxtaposing the Perceived Barriers and Support Strategies Used by Women in Leadership Positions in South African Universities
}

\author{
Anita Maürtin-Cairncross (Ph.D) \\ Manager: Academic Leadership and Communications \\ University of the Western Cape \\ amaurtin-cairncross@uwc.ac.za
}

\section{Doi:10.5901/mjss.2014.v5n8p558}

\section{Abstract}

Many of the challenges experienced by women have their origins in the patriarchal notion of the private/public divide and stereotypic notions of 'male' and 'female' work and roles. These traditional notions of 'man's work' being in the public sphere (characterized by dealings with matters of the mind), and 'woman's work' in the private sphere (characterized by dealings with emotional matters), continue to have salience in contemporary societies. The research is couched within the feminist standpoint theory which was used as the conceptual framework for the article. This study provides an overview of perceptions of women in leadership positions in South African Higher Education with regard to the barriers they experiences and the strategies they use to support them in these positions.

Keywords: Women, Higher Education, leadership positions, androcentric cultures, gendered careers, 'double load', 'mommy track', feminist standpoint theory.

\section{Introduction}

Despite myths concerning the efficacy of affirmative action programs, there are still relatively few women in academia... educational cutbacks with fewer permanent positions and more restrictive criteria for promotion have given rise to the 'revolving door' phenomenon, wherein junior staff are rotated through entry level positions without serious consideration for permanency. This has created a new class of 'gypsy scholars ' an intellectual 'proletariat', who, in order to earn a living - move from one low-paying, dead-end teaching post to another. This proletariat is disproportionately female. ..... There is undoubtedly truth in explanations that women are still primarily responsible for child-rearing and homekeeping. But, by focusing solely on these external factors, may lead one to overlook the ways in which sexism, is embedded in the structures, norms and policies of the university itself. (Madsen, 2012; Hewlett and Buck Luce, 2005; Park, 1996; Tomas, Manuel, Lavie, de mar Duran \& Guillamon, 2010).

This is evident when considering the number of women in executive positions in South African universities, as reported in the data available from the Department of Higher Education and Training and illustrated in Table 1, below.

Table 1: Number of women in executive positions in South African Universities

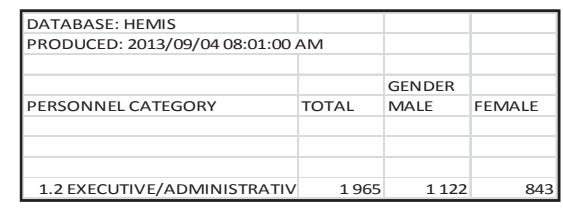

The data indicates that in 2012 only $42 \%$ of executive positions in universities are occupied by women. The rationale was to conduct a study to gain an understanding of the perceptions of women in leadership positions with regard to barriers and support mechanisms they experience in their roles at some South African universities. This research study explores:

- the barriers women in leadership positions experience in Higher Education

- what proposals they would recommend to institutions to 'feather the nest' for them in their positions and

- strategies they use to support them in their positions.

This article, however, only reports on the first and third point, namely, the perceived barriers to women in 
leadership positions in Higher Education institutions and the strategies they use to support them in these positions. An article 'Feathering the nest: some perceptions by women in Higher Education about the need for the development of institutional structures to support them in leadership positions' provides the findings of the second aspect of the research project.

\section{Literature Review}

\subsection{Current trends in the interpretation and reconceptualization of feminist standpoint theory}

The reconceptualized feminist standpoint theory has many features of feminist post - modern theories such as social constructionsim. Post-modern theorists have their genesis in the works of scholars of the middle and late 20th century who contested the principles of modernity. Hence, it is argued that the origin of knowledge is socially constructed and there is a preference for local narratives. This perspective therefore offers opportunities for the representation of voices and stories of people and social groups that were traditionally silent and silenced. Current understandings of feminist standpoint theory reflect the key tenets of post-modern theories that suggest that a critical position be adopted for the 'taken for granted' ways in which reality is understood. It challenges the idea that that conventional knowledge and understanding is based on an objective, unbiased observation of the world has been widely developed (Collins, 1997; Harding, 2004; Nicholson, 2013).

The major shift in the interpretation of feminist standpoint theory is that contemporary feminist standpoint theory draws on post-modernism and post-structuralism in particular, to acknowledge diversity. Current interpretations of feminist standpoint theory is therefore underpinned by the recognition of differences between women and the acknowledgement of women's various axes of subjection that have been highlighted by postmodern feminists (Harding, 2004, Ratcliff, 2006) In this interpretation, feminist standpoint theorists do not attempt to totalize and unify women and the 'woman's experience'.

Harding (1991) argues that feminists need to replace the desire for unity with regard to women's common experiences, with goals shared by other groups struggling against Western hegemony. The 'new version' of feminist standpoint theory acknowledges differences in experiences of women, and encourages them to establish their own standpoints. When feminist standpoint theory is interpreted in this way, this theory becomes an epistemological position and not a methodological movement.

Feminism has been positively accepted by many post modernists and other 'counter-hegemonic' theorists, because these theorists too, are concerned with questioning, exposing and rectifying flaws in traditional research frameworks. According to these theorists, the major objective of any research endeavour should be to create knowledge that facilitates transformation of the social order as desired by the participants of the research. Feminist inquiry is a paradigmatic shift countering the reigning ideology. For Harding (2004) argues that science is socially constructed in that those who are involved in decision making and are thus socially embedded and not by those who are socially peripheral.

Feminism's history as a critique of patriarchy can be understood in terms of the ways in which it addresses gaps in the dominant culture's ways of making sense of women's lives. (Hennessy,1995, Ratcliff, 2006). Critique aims not to heal or resolve cultural crises, but to reveal that the internal contradictions in a cultural text are the products of crises in the social order at large. These internal contradictions cannot be resolved by the system as configured at present. Harding asserts that not only is there no 'typical woman's life', but women's experiences of their lives are not necessarily the feminist knowledges of women's lives (Harding, 2004; Nicholson, 2013). Although the reliability of this theory may be challenged, the theory provides a space for women's voices to be heard. It also provides an opportunity for women's experiences and opinions to be raised and documented; unlike traditional social research where women were outside the research arena (whether as subjects or as objects).

For feminist standpoint theorists, the term 'woman' does not imply that there is sameness among all women. Rather it argues that that other areas of invisibility and inequality interweave the theoretical invisibility and inequality of women: such as class and race, amongst others. Feminist standpoint theory, with this understanding, is not seen as a means by which to give identity to women only, but as a campaign that challenges the dominant ideology (Harding, 2004; Hennessy, 1995). This disidentifying subject of critique does not claim any one group identity as its sole terrain, but instead 'speaks from' the position of a counter-hegemonic collective which its theoretical framework produces. The place for feminist standpoint theory, from this perspective, is not 'experience' as we are used to thinking of it, but an articulated system of positions in the historical process. The contemporary interpretation of feminist standpoint theory does not aim to eliminate differences, but rather to ensure that differences are not used to support unequal power relations. Feminist standpoint theory calls for a definite restructuring of the political and economic structures which are supported by the 
existing social order (Harding, 1991; Hartsock, 1998; Hennessy, 1995). For these reasons, feminist standpoint theorists are now regarded as being concerned with the multiple axes of oppression that women experience rather than with the single axis of gender as the only form of subjection and oppression that women experience. Arguably, there are various feminist standpoints because there is no single standpoint which would adequately address the concerns of all women.

By using the 'new interpretation' of feminist standpoint theory, researchers need not be apprehensive that feminism may lose its specificity. The central tenet of feminist standpoint theory remains to be launched from an inquiry into and the opposition of the devaluation of 'woman' under patriarchy. In this way, feminist standpoint maintains the specificity of its starting point and special interest (Harding, 2004;Nicholson, 2013; Reay, 1996a, 1996b). Contemporary feminist standpoint theory may therefore be regarded as a conceptual framework which allows subjects of feminist research to be transformed from an empirical group of 'women', to a collective epistemology of critique aimed at dismantling the patriarchal social order (Harding, 2004; Hennessy, 1995).

The selection of the feminist standpoint theory as a conceptual framework for this study achieves two goals. Firstly, to provide a platform for women's voices and experiences. Secondly, this framework allows for the interpretation of women's experiences not only from their marginalized positions due to gender but also from other axes of subjection. Using this perspective, women's relationship to power and their access to 'centers of power' are also brought into sharp focus. By using the principles of contemporary feminist standpoint theory, 'voices from the margins' may be articulated. In this study, women in leadership positions, in the academy, were able to articulate their 'experiences'. By completing the survey-questionnaire, the participants were provided with an opportunity to articulate their experiences and make indicate the support strategies they used to support them in their positions and the 'dailiness' of their lives to fulfil their leadership roles.

Contemporary feminist standpoint theorists acknowledge difference and diversity and make provision for various 'standpoints'. From this stance, feminist standpoint theory does not totalize and unify all women to a single category of 'woman' as was discussed earlier. It is hoped that this theoretical framework will facilitate an enriched and deeper understanding of academic women's reports with regard to the challenges they experience in their leadership positions.

\subsection{Contextualizing women in academia as workers}

It is commonly acknowledged that women in academia, like women in the broader work context, often encounter more barriers to their career advancement than do their male counterparts (Aisenberg \& Harrington, 1988; Crosby, 1991; Hewlett \& Buck Luce, 2005; Madsen, 2012; Morley et al., 2001; Park, 1996; Subotzky, 2001). The notion of gendered governance refers to the way in which men and women learn what is valued as well as participation in decision making. Such learning frequently determines their roles and identities in the social order and their perceived entitlements as members of a given society.

While there is a global trend of more women academics in universities, there is a sharp awareness that women are still underrepresented at higher levels and in positions of power in the academy, and that most women are employed in the lowest positions in the academy (Bagilhole, 2000; Morley et al., 2001; Park, 1996;). As a consequence, women in academia often have a sense of being 'short-changed' in terms of promotion and escalation on the 'academic ladder. Women's late entry into the academy has apparently had a continued influence on the position of women academics and on the governance of universities.

The components of academies that contribute to the culture of the academy include aspects of curriculum development, appointment and promotion processes, style of academic surroundings and the hierarchical structure (Park, 1996). Because it may be argued that academies were designed by men for men, a gendered and androcentric culture remains prevalent at these institutions (Subotzky, 2001). The emphasis on efficiency and effectiveness in Higher Education has resulted in minimal attendance to matters concerning gender equity: for example, Historically Black Universities (HBUs), in South Africa have, since their inception, had to contend with inequalities on multiple levels, especially during the apartheid regime. These inequalities, related to resources, funding and programmes, were deemed as more crucial than matters pertaining to gender justice. Managerial bodies of HBUs, who were predominately male, continued to create the 'othering' of women in these academies (Subotzky, 2001). Although some men deny a gender equity problem, the experiences of South African academic women reflect subtle forms of gender discrimination which are consistent with international trends (de la Rey, 1999; Madsen 2011, Olaide Oti, 2013). Even successful senior women perceive their roles in the academy as invisible and express disillusionment with their institutions when their hard work is not recognized (de la Rey, 1999; Morley et al., 2001).

Globally there has been a marked clustering of women undergraduates, postgraduates and academic staff in particular disciplines. However, it is apparent that there is a dramatic elimination process when women attempt to 
escalate through the academic hierarchy (Bagilhole, 2000; Morley et al., 2001; Subotzky, 2001). In addition to horizontal gender segregation between the disciplines, vertical segregation marks the difference between male and female staff members in the academic hierarchies, especially in terms of remuneration in institutions where women are paid on lower salary scales than men. Increasingly, and more often, it is women who are appointed on 'soft funding' as lecturers, or as research staff who are part-time, or on short-term contracts (Park, 1996). A review of literature on working women highlights a number of key areas believed to impact on their work and hinder their ability to progress. These include the 'double load'; androcentric culture and gendered careers. Because many challenges that academic women encounter in academia have their origins in traditional patriarchal practices, it becomes important to problematize these challenges more broadly.

\subsection{The "Double Load" role of women in leadership positions}

Although the majority of women, across the globe, are employed outside the home, they are still primarily responsible for child-rearing and home-making activities. This has traditionally been referred to as the 'double load' or the 'juggling act', which women evidently experience on a far greater scale than their male counterparts (Aisenberg \& Harrington, 1988; Crosby, 1991). Historically, an academic career was perceived to be a career option which lent itself to combining motherhood and work. This is because the hours are flexible, the work has a degree of autonomy and for many academic women staff members the holiday periods coincide with the school holidays (Park, 1996; Welch, 1990). In recent times, this career option has become less favourable to women because of diminishing resources, lower salary scales than for many other occupations and the strong competition for permanent positions (Bagilhole, 2000; Park, 1996; Subotzky, 2001). Managing a career, a home and being an effective parent has been identified as a major challenge for women in academia (Henry, 1990; Park, 1996; Welch, 1990). Women's 'juggling' may involve decisions that affect families and not only the 'juggler', but there is often the perception that the challenges that confront families are regarded as challenges for women.. The way in which women regularly juggle roles is exemplified by the following description of the various roles of a part-time woman student, has to juggle throughout her day: while she is enacting one set of roles (employee, colleague, friend), another set of roles must disappear from the center stage of her life (student, tutor); yet another set of roles may constantly remain, receiving attention at different levels, with differing degrees of involvement at different times of the day (these are the roles of mother, wife, nurturer and comforter). From this example it becomes evident that many women find it difficult to acquire the resources to meet all demands of any one role. Consequently, it has become even more difficult to find the resources to meet the demands of multiple roles (Crosby, 1991).

Researchers report that difficulties often relate less to personal inadequacies, than to the untenable situations in which women find themselves. Although women have always 'juggled' with their various roles, in contemporary times employed women have been found to experience more difficulty in the 'juggling act'.

'Juggling' is a special form of role combination because it entails the enactment of a multiplicity of roles on a daily basis. This often results in high levels of stress as well as physiological and psychological exhaustion ('burnout') (Bagilhole, 2000; de la Rey, 1999; Subotzky, 2001). Psychologists explain that in contemporary times, people live particularly ordered lives without much 'leisure' or 'optional time' periods (Crosby, 1991; Welch, 1990). Given the fact that women still bear the primary responsibility for both the care of children and the management of the household, the intensity and the number of roles for which women are responsible often contribute to more strain on mothers than on fathers (Hewlett \& Buck Luce, 2005)

Juggling may result in feelings of insecurity and a slower progression on the career ladder because when women join the work force, they do not always relinquish their home responsibilities. For some women, work outside the home is often not experienced as a liberating experience, but rather as an added burden.

It is conceivable that for as long as society identifies difficulty in juggling as solely the problem of women, the challenges that women experience in every role they enact, are ignored. Furthermore, it is argued that the emphasis on inter-role conflict serves to maintain the status quo, where men are expected to remain on the peripheries of homemaking activities (Crosby, 1991; Hornsby, Morrow-Jones and Ballam, 2012, Hewlett and Buck Luce, 2005; Madsen, 2012).

\subsection{Androcentric Institutional cultures}

One of the primary barriers that women are reported to experience in the academic setting is the historical dominance of male, androcentric culture. This refers to both the reproduction of gender power relations between men and women as well as a culture which assumes the centrality of men and 'masculine' values (Castillo, Baltodano, Carlson, Witcher Jackson and Mitchell, 2012; Chant \& Gutmann, 2002; Madsen, 2011, Hornsby et al., 2012;. These cultures are the 
consequence of historical patriarchal norms which determined the social order. The concept of homosociality has been used to analyze the way in which men and traditional male values continue to dominate institutions, even when women are present. Homosociality usually refers to 'male bonding' which tends to be the bonding of men of the same race, religion and social class.. It has been widely argued that in male-dominated settings, there is a tendency for men to 'close ranks' and only recruit and select men, rather than women, for successors to (often) senior positions (Bagilhole, 2000). This has been popularized as the 'People-Like-Us Syndrome' (PLU). Researchers report that the reason that men's successes are often more easily accepted, while women's career successes are questioned, is that men are similar to the people on the selection committees and decision-making bodies of academies. In this way organizational androcentricity is left unchallenged and reproduced (Bagilhole, 2000; Hornsby et al., 2012). PLU theorists maintain that similarity creates empathy and trust. It is argued that women are regarded as untrustworthy in the field of academia, as they are in other androcentric workplaces (Acker, 1990; Halsey, 1992).

\subsection{Strangers in the sacred grove}

Another conceptual framework used to describe androcentricism in organizations is that of 'strangers and outsiders' (Aisenberg \& Harrington, 1988; Hewlett \& Buck Luce, 2005). A common and central thread of the aforementioned conceptual frameworks, is that of women being perceived and women perceiving themselves to be 'outsiders' to the centers of powers in an organization. Consequently, in metaphoric terms, women are regarded as strangers in a foreign land. The concept of women as 'strangers and outsiders' in a work environment, has particular salience in the academic setting (Aisenberg \& Harrington, 1988; Walker, 1998). Many authors and researchers metaphorically likened the academy to a foreign country, where men are the natives in the country, in which women who enter into these 'regions' are likened to immigrants, foreigners or strangers. As 'strangers', their intentions, experiences and involvement are not always completely trusted (Bagilhole, 2000).

It is also argued that academic women have to work harder and receive more achievements than men would have to, in order to have their academic credibility acknowledged (Morley et al., 2001; Subotzky, 2001). As strangers and newcomers to the academy, women are often excluded from social relationships (Evans, 1996). Such social lives then evolve into 'old boys' network' versus women in the 'outer circle' in academia. It is conceivable to conclude that the marking and maintaining of these boundaries serves to strengthen the sense of belonging of men as 'insiders' (Evans, 1996). It is therefore conceivable that women experience professional marginalization and exclusion from the centers of professional authority.

When one continues with the notion of the academy being regarded metaphorically as a landscape, the tribes of the academy are said to define their own identities and defend their own patches of intellectual ground by employing a range of strategies geared to exclude 'immigrants'. It is therefore not surprising that Acker (1994) classified women as 'other' academics, who often experience not so much overt discrimination, but the everyday practices of exclusion that are more subtle, more deeply ingrained and more difficult to contest and resist (Bagilhole, 2000; Evans, 1996; Halsey, 1992; Wilson, 1999). As a 'muted' group women learn to express their ideas in terms of the dominant group so that they suppress and repress alternatives. Delamont $(1989, p .252)$ draws on Bourdieu's concept of the 'habitus' to explain these difficulties experienced by women:

Mastery of the habitus is treated by initiates as a matter of natural talent, of personality, of the 'virtuality' of the practitioners. That is, part of the essential performance skills of the occupation is never explicitly taught but is believed to be innate, natural, inborn and personal.

In this way the habitus obscures the subtle barriers, the 'clubbiness', while leaving the technical aspects of the profession visible. This often causes women to be mystified when they meet the technical demands of academic tasks, yet still fail to advance to the upper echelons because they have fallen short on the 'mastery' of the academic occupational culture (Halsey, 1992; Walker, 1998). Women academics find their academic identities validated, or not, by those with both institutional and social power in universities.

Such marginalization is not surprising when one considers that even as recently as 1989 , books published by the Society for Research into Higher Education, make use of 'gender insensitive' referencing. In his book Becher (1989,p. 58) refers to:

Even among the few who reach elite status during their professional careers, there are few who achieve the recognition as great men. .....because judgments of the highest quality can only be made by men who are already eminent, those at the top of various informal scientific hierarchies exercise great influence over the standards operative in their fields 
This author included the role of gender as contrite concluding notes to a chapter in his book (Becher, 1989,p. 126). The concept of women as 'strangers' in the academy manifests itself in several other assumptions. One of these assumptions is that women generally are less productive, in terms of publishing, academic management and problem solving (Bagilhole, 1993; Becher, 1989; Toren, 1999). But these assumptions have been disputed by research findings (Toren, 1999) that reveal that women allocate more effort to academic work than men with similar family status do:

\section{Women add work roles to their family roles, they generate the energy necessary to fulfill their commitments to the two} sets of activities (p. 6).

These patriarchal assumptions were used to rationalize discrimination against women in terms of hiring, promotion and inclusion into informal collegial networks, the infamous 'old boys' club' (Acker, 1990; Bagilhole, 1993; Park, 1996; Subotzky, 2001). In order to move up the academic ladder, woman's worth has to be recognized and encouraged by those in the upper echelons of academic institutions (Evans, 1996; Morley et al., 2001; Subotzky, 2001).

Another conceptual framework used to describe androcentricism in organizations is that of 'strangers and outsiders' (Aisenberg \& Harrington, 1988; Toren, 1999). A common and central thread of the aforementioned conceptual frameworks, is that of women being perceived and women perceiving themselves to be 'outsiders' to the centers of powers in an organization. Consequently, in metaphoric terms, women are regarded as strangers in a foreign land. The concept of women as 'strangers and outsiders' in a work environment, has particular salience in the academic setting (Aisenberg \& Harrington, 1988; Toren, 1999). Many authors and researchers metaphorically likened the academy to a foreign country, where men are the natives in the country, in which women who enter into these 'regions' are likened to immigrants, foreigners or strangers. As 'strangers', their intentions, experiences and involvement are not always completely trusted (Bagilhole, 2000).

It is also argued that academic women have to work harder and receive more achievements than men would have to, in order to have their academic credibility acknowledged (Morley et al., 2001; Subotzky, 2001). As strangers and newcomers to the academy, women are often excluded from social relationships. Such social lives then evolve into 'old boys' network' versus women in the 'outer circle' in academia. It is conceivable to conclude that the marking and maintaining of these boundaries serves to strengthen the sense of belonging of men as 'insiders'. It is therefore conceivable that women experience professional marginalization and exclusion from the centers of professional authority.

Consequently, despite women's increased participation in traditionally male-dominated occupations and claims of reductions in the 'gender gap' in human capital and work experience, women in academia are still often regarded as 'strangers in the Ivy Tower' (Subotzky, 2001;). There should be an acknowledgment that new norms do not readily replace old ones, because deeply embedded beliefs are slow to change. Commonly tensions between the new and the old norms cause points of conflict (Subotzky, 2001) and in this way serves to exclude women from these networks. These networks indicate where information pertaining to the 'unwritten rules for promotion' is shared. Because women are often not included in these inner circles, they are marginalized in this process. This results in the production of an academic culture that is sustained by male bonding and assumed understandings. In this way men share traditions, styles and understandings about competing, and succeeding. This is the relevance of homosociality in academia. This is a point at which women in the academy are often caught in the proverbial crossfire. On the one hand, if they pursue their academic careers by following the rules and practices (for example, aggressive and competitive traits), established by male practitioners, they offend the traditional norms that were used to define womanly attributes. On the other hand, if women behave according to old female norms, (being patient, nurturing, smiling and soft-spoken), they appear to be weak. Often these feminine traits prevent them from attaining senior positions in the academy (Subotzky, 2001; Tomas et al., 2012). This is the dilemma of women in the academy because they do not easily fit into either of the conventional moulds: not into the mould of 'womanliness' nor into the prevailing mould of male 'professionalism' or male manager (Wilson, 1999). These are the stereotypes which academic women have to encounter in the academy, as well as in the broader society.

This 'cross fire' experience is the most evident at the higher rungs in the academy because it is in these positions where women experience 'glass ceilings ' that prevent them from reaching the most senior positions. This accounts for the reasons that women are more likely to be members of departmental and faculty committees than to serve as members on governing boards and councils.

It is argued that these conceptual frameworks provide a framework for understanding the 'othering' of women's career tracks when compared to the progression of male career patterns. The culmination of these 'othering' experiences elucidates the perception that there are 'hidden passages' to progress on the academic ladder. These hidden passages negatively affect academic women's career progression (Bagilhole, 2000; Hornsby et al., 2012). The 'othering' and 'outsiderness' experienced by women contribute to their marginalization in the academy and may also contribute to 
problems with promotion, once entry to the academy is achieved (Evans, 1996; West \& Lyon, 1995; Wilson, 1999).

\subsection{Gendered careers}

It has been argued that the term 'career' itself is a gendered concept in which men's career patterns are predominantly regarded as the norm, while 'other' career patterns are viewed as deficient or lacking (Evertts, 1994). When the 'normal' model of career is constructed to be one of continuous service and regular promotion to positions of increased responsibility, career paths that are not consistent with this model are regarded as 'imperfect'. Because women's reproductive roles and family responsibilities do not always allow them to 'fit' into traditional requirements of 'normal' career paths, women often have careers that tend to be 'other' and valued less than the male norm (Acker, 1984; Hewlett and Buck Luce, 2005). On the other hand, men's uninterrupted linear careers are rewarded and make them eligible for promotion. For these reasons they continue to predominate in the senior positions of organizations and professions (Evetts, 1994; Hewlett \& Buck Luce, 2005).

Furthermore, there is a tendency to assess career success in terms of promotions to higher positions (Evetts, 1994). Many women and some men may desire rewards other than advancement, from their work. For example, there are teachers who prefer to remain in the classroom rather than to be promoted to managerial (non-classroom) positions. A further example is found in nursing, where there are nurses who prefer patient-contact to administration, even though the latter is perceived as more prestigious and is better rewarded. A significant consequence of the hierarchical model of career is the devaluation of the work, and the possible down-grading of salaries, of those who fail to seek or fail to achieve promotion in their careers (Welch, 1990).

A further limitation of the gendered assumptions linked to careers is that they are only developed in the sphere of paid work (Evetts, 1994; Park, 1996). In this understanding, careers are only constructed and developed in occupations and professions. Activities other than paid work do not always contribute to promotional skills or promotional entitlements. Because 'career women' frequently strive for equality at all levels in workplaces, there is often a perception that a viable route to equality is through the economic system, especially in terms of evaluation of salaries and promotions (Hewlett \& Buck Luce, 2005; West \& Lyon, 1995). Using this argument, homemaking tasks, because they are often unpaid or underpaid activities, are not as valued as paid occupations. Similarly, community-oriented tasks in which many women are involved, are also seldom acknowledged. The lack of prestige and the low value attached to these types of activities are evident in the academy where the 'community outreach' component of the work load of academics, is not as highly valued as publishing as a promotion criterion (Bagilhole, 2000; Park, 1996).

The 'mommy track' is a popular conceptual framework utilized to explore the ways in which women's careers have been constructed. This framework makes reference to the marked difference between the career tracks of professional men and women (Aisenberg \& Harrington, 1988; Crosby, 1991;Hewlett \& Buck Luce, 2005). The mommy track, which is supposedly the career track of many professional women, has been described as being characterized by more commitment to family responsibilities than to work activities, slow promotion in the organization, utilization of leave options and difficulty in juggling (Aisenberg \& Harrington, 1988, Crobsy, 1991; Hewlett and Buck Luce, 2005 ). Traditionally, corporate businesses and the public sector did not offer permanent employment to married women or mothers.

In contemporary times, many countries have embraced the concept of Employment Equity (EE). The practice of not offering permanent employment to married women is now regarded as a form of discrimination. However, a covert, or even an openly acknowledged alternative, 'mommy track', has replaced these discriminatory practices. This option affects the career tracks of women in several ways. On the one hand, it offers flexible working hours, part-time options and liberal maternity leave benefits to women, but not to men. This often places women in an invidious position, because when women do make use of these options, their commitment to the achievement of senior positions, is questioned. Also problematic is the fact that this 'track', is seldom available to men: family pressures and responsibilities are not perceived to be 'men's responsibilities' (Henry, 1990). It can therefore be argued that the 'mommy track' reinforces the traditional status quo in that its assumptions are that 'men's work' is public, while family responsibilities are primarily 'women's work' (Harper et al., 2001; Park, 1996).

It was found that 'mommy tracks' are not the only way in which most women executives and professionals who have children organize their careers (Aisenberg \& Harrington, 1988). Many professional women often planned and timed both marriage and childbearing. Career women were frequently found to have assistance in child-care and homemaking. Some women find themselves compromised by the option of the 'mommy track' because, on the one hand, when they put their families before their careers, they felt that they were responding to a cultural norm that is mediated through direct pressures from their husbands or partners at home, and from other people's husbands in the workplace. But on the other 
hand, when women do not make the 'correct choice' to put her family before her career, both she and her husband or partner are often criticized by peers and colleagues (Bagilhole, 2000)..

When professionals choose to use the options of paid leave and reduced working time, it often causes 'career derailment' and 'career plateauing' (Aisenberg \& Harrington, 1988; Consequently, women who want to progress in their careers, often avoid the use of these options. It has been argued that this 'track' was created to derail women who were on the 'fast track' to senior positions (Aisenberg \& Harrington, 1988). From this perspective, the 'mommy track' retains women in lower-paid and less prestigious positions. The implicit assumption of the developers of the 'mommy track' is that women are not capable of simultaneously dealing with the responsibility of leadership and the responsibility of their family's well-being. In the current stratification of careers in work organizations, this policy construction has been very destructive to women who opt for these choices. Furthermore, the negative stigma attached to the use of leave options has also constrained men's use of leave and part-time work. 'Mommy tracks' thus legitimize the 'glass ceiling'. The cumulative effects of these processes of exclusion often reinforce and justify stereotypes and prejudices that disadvantage women in workplaces.

Thus the 'mommy track', although it provides an option that may alleviate the 'double load' for women, may also be interpreted as a 'track' which is parallel and less valued than the 'normal' career track (which men normally use). It is therefore evident that women in leadership positions in Higher Education often experience 'the chilly climate' of the institutional cultures and report that they experience barriers where they feel like outsiders and thus make use of various strategies to support them in their positions.

\section{Methodological Considerations}

\subsection{Research Paradigm}

This section outlines the theoretical underpinnings of the study, which although located within a feminist theoretical framework, draws primarily on the principles of the feminist standpoint theory. This paper focuses exclusively on experiences of in leadership positions with regard to their views on the proposals for institutional support structures. Given this focus, this section outlines the key tenets of feminist standpoint theory and its value to this particular study. In essence, feminist standpoint theory has three makes three principal tenets. Firstly, according to these theorists, is that knowledge is socially situated. Secondly, that marginalized groups are socially situated in ways that make it more possible for them to be aware of things and ask questions than it is for the non-marginalized. And, finally, that research, particularly that focused on power relations, should begin with the lives of the marginalized. Feminist standpoint theories place relations between political and social power and knowledge center-stage. These theories are both descriptive and normative, describing and analyzing the causal effects of power structures on knowledge while also advocating a specific route for enquiry, a route that begins from standpoints emerging from shared political struggle within marginalized lives (Denzin \& Lincoln, 1998; Olesen, 1994).

\subsection{The data collection method and procedures}

The survey questionnaire containing three open-ended questions were sent by e-mail to approximately twenty women in leadership positions or had previously occupied leadership positions in South African Higher Education institutions. The sample was a convenient one as it was purposive because the respondents were accessible and available to the researcher who is working at a Higher Education institution. The three open-ended questions were: Firstly, 'what do you regard as barriers /challenges to women's leadership in Higher Education?' and secondly, 'which strategies you would recommend to Higher Education institutions to develop to support women in leadership positions in these institutions?'. The third question was 'which support mechanisms you use in your leadership position to deal with challenges related to the position '. Respondents were requested to provide three responses to each question. The findings presented in this article will focus on responses to questions one and three, respectively, namely, what do you regard as barriers /challenges to women's leadership in Higher Education? and 'which support mechanisms you use in your leadership position to deal with challenges related to the position? The responses to the other questions will be disseminated in another article, as mentioned previously.

The qualitative data was analysed done using thematic discourse analysis which was conducted using the themes that emerged from the responses. 


\subsection{Ethical considerations}

In the e-mail, the researcher assured the respondents who were all known to her, of the confidentiality and anonymity of their responses. The sample size is relatively small as the findings of study were intended to provide a 'snap shot' of perceptions of women in these positions. The response rate was $85 \%$.

\section{Results and Discussions}

\subsection{The respondents' biographical data}

Respondents were from both the administrative sector as well as the academic sectors, respectively, in Higher Education institutions. The lecturers included in the sample had been in leadership positions in their departments in recent years. Table 1 provides the diagrammatical representation of the positions of the respondents.

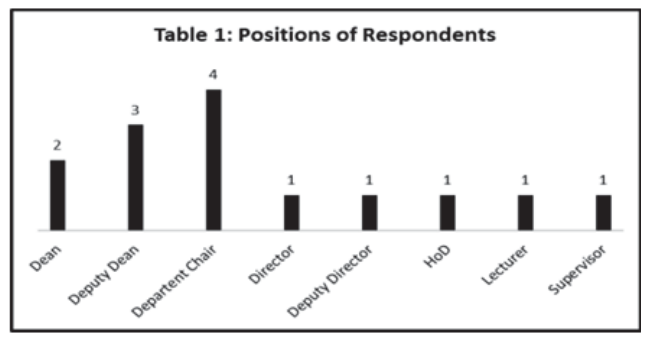

Figure1 provides a description of the respondents across historical racial categories. Two respondents (11.8\%) of the respondents were White while $12(70.6 \%)$ were Coloured ,while only one African woman (5.9\%) responded to the questionnaire. This data set is provided merely as a description of the respondents and not as variable for interpretation in this paper.

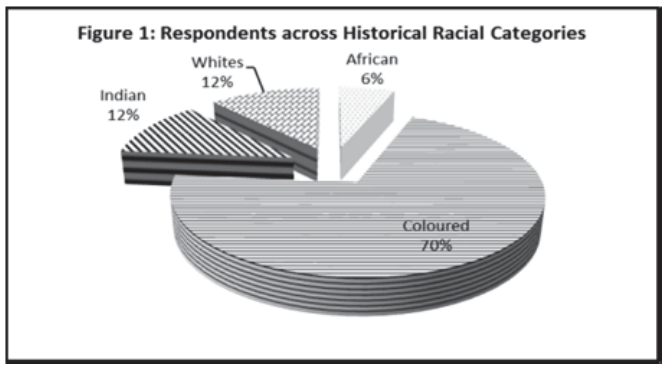

\subsection{Qualitative findings and discussion of themes}

There were specific themes that emerged from the data obtained from the responses. Some of themes relating to the question relating to the barriers included: respondents feeling undervalued; the experience of outsider to 'old boys club' and androcentric cultures, lack of support by executive and senior leadership and the work-life balance (double load and the 'mommy track').

\subsection{Perceptions of feeling undervalued and not supported by senior /executive management}

The responses indicated that women felt undervalued in their roles. Many of these responses are closely intertwined with the other theme of lack of senior support by senior leaders. Some excerpts to illustrate this theme are:

...Women appointed to positions where their workload /teaching load is higher; women dealing more with day-day issues seen as 'softer skills". Assertive women perceived as bossy, difficult (Respondent 15) 
.... expectations are also linked to issues of authority and power more especially in terms of your authority being recognised by both senior men and women. There is a sense in which the men can do the more and bigger things, while the women have to be content with the smaller things (linked to soft/hard sciences distinction) (Respondent 11).

These responses indicate the experiences of marginalization in the androcentric cultures of Higher Education where women's gendered careers are reported (Acker, 1984; Hewlett \& Buck Luce, 2005).Furthermore, it alludes to according to feminist standpoint theorists, the multiple axes of oppression that women experience rather than with the single axis of gender as the only form of subjection and oppression that women experience (Harding, 2004; Hartsock, 1998; Hennessy, 1995, Nicholson).

These reported experiences are what the literature refers to as women being strangers and outsiders to the academy and as 'strangers', their intentions, experiences and involvement are not always completely trusted (Bagilhole, 2000; Walker, 1998).

...Not acknowledging that you have the capability to lead and the barrier of what will they say or think if I do anything that I perceive as leading (Respondent 8).

The respondents also directly expressed that they did not feel supported by the senior management of the institution as is evident from the following quotations:

... Transparency from senior management is questionable. This hampers your perceived 'transparency' (perceived by own staff). Women have to work extra hard to be taken seriously by senior management. As an associate professor, I am still referred to as "junior" by some in senior management. (Respondent 14)

...lack of support from management (Respondent 17)

These comments thus concur with the literature that even successful senior women perceive their roles in the academy as invisible and express disillusionment with their institutions when their hard work is not recognized (de la Rey, 1999; Morley et al., 2001; Subotzky, 2001).

\section{4 'Double Load' and the 'Mommy Track' of women in academia}

The respondents referred to women's private, family and personal lives which sometimes is regarded as a barrier. The literature makes reference to this as women's 'convoluted' career trajectories, rather than linear career paths (Aisenberg \& Harrington, 1988; Hewlett \& Buck Luce, 2005). De la Rey (2001) refers to women's careers which may result in 'late bloomers' as women often reach senior positions in their careers at a later stage than men due to 'convolutions', for example, having babies, caring for parents and general nurturing and caring responsibilities which are often socially embedded into the roles of women (Harper et al., 2001; Park, 1996).

The following excerpts illustrate how the respondents experience the 'double load' and the 'mommy track' as barriers in their leadership positions:

\section{... another barrier is that often women do not apply for positions as they are in private spaces which are not conducive to them taking on leadership positions (Respondent 11)}

Several scholars indicating to manage a career, setting up a home and being an effective parent has been identified as a major challenge for women in academia (Henry, 1990; Park, 1996; Welch, 1990). This was echoed by Respondent 7 that the usual challenge of work-family balance is a huge challenge for them. Leadership positions in HE often entail long hours and work brought home in the evenings and weekends is considered the norm. I think that with massification of HE and reduced funding, academia is becoming a more demanding profession; most of my colleagues women and men- are working long hours, over committed etc. Moreover, it may be argued that historically, an academic career was perceived to be a career option which lent itself to combining motherhood and work of most women. I think in this context, more women will therefore avoid leadership roles, due to family commitments. Respondent 5 have the following to say:

Having to balance / juggle family and work - women have a much heavier load in contributing to family life; time-off to be with children is the women's domain (maternity leave; handling kids when they are small). Women in leadership positions who do not have child minding responsibilities - appear to be doing better career-wise. ... thus the perceptions with regard to women having to go off to have 'babies' or that women are not strong enough - as such women are overlooked for promotion.. 
Crosby (1991) concurs that although women have always 'juggled' with their various roles, in contemporary times employed women have been found to experience more difficulty in the 'juggling act'. This sentiment is echoed by ...family responsibilities in conflict with work responsibilities (Respondent 17).

... many women experience career breaks due to child rearing responsibilities or the need to support the career aspirations of their partners which may mean shouldering all childrearing responsibilities regardless of whether they do experience career breaks (Respondent 2).

..lack of support, difficult start and ending times sometimes when family duties also call and one lives far away and has to leave children at school before anyone else; prevalent attitude that you must adopt male strategies to get anywhere or get anything done (Respondent 9).

\title{
4.5 Experiences of being outsiders in androcentric cultures
}

It is evident from the respondents' view that they, as women, experience feelings of 'outsiders' in male-centred (androcentric) cultures.It may be argued that academies were designed by men for men, a gendered and androcentric culture remains prevalent at these institutions. Although some people deny that there is a gender equity problem, the experiences of South African academic women reflect subtle forms of gender discrimination which are consistent with international trends (de la Rey, 1999; Madsen, Longman \& Daniels, 2012; Olaide Oti, 2013). Even successful senior women perceive their roles in the academy as invisible and express disillusionment with their institutions when their hard work is not recognized (de la Rey, 1999; Morley et al., 2001; Subotzky, 2001).

Here too, the value of using the feminist standpoint theory is elucidated because by using this conceptual framework, the research is able to be focused on power relations, which has its genesis in the lives of the marginalized. Feminist standpoint theories place relations between political and social power and knowledge center-stage.

In the following quotations the respondents report on their experiences of 'othering':

... another barrier to grow the number of women leaders in HE is their own self-limiting beliefs. They may lack the confidence of their male counterparts who are more willing to be bold and take a risk and apply for senior positions regardless. (Respondent 2)

... Although this is 2013, it feels or is perceived that senior management is still a bit of an "old boys club" (Respondent 14).

As is evident from these responses, the concept of homosociality as described in the literature is experienced by the respondents and they experience how men continue to 'close ranks' when recruiting for senior positions. Furthermore as supported by the literature, is that the reason that men's successes are often more easily accepted, while women's career successes are questioned, is that men are similar to the people on the selection committees and decision-making bodies of academies (Bagilhole, 2000). In this way organizational androcentricity is left unchallenged and reproduced (Hornsby et al., 2012). Many authors and researchers metaphorically likened the academy to a foreign country, where men are the natives in the country, in which women who enter into these 'regions' are likened to immigrants, foreigners or strangers. As 'strangers', their intentions, experiences and involvement are not always completely trusted.

The excerpts that follow attest to the experiences of 'othering' and outsiderness'

\begin{abstract}
...Responsibilities/areas with status of often kept closed and there is a sense of "letting some women in" and they are so grateful that they are prepared to do the menial work of the responsibility/task. What has become noticeable is that some women have taken on a role where they behave in a manner that men were accused of in terms of not sharing, holding on to power, acting as gate keepers etc (Respondent 3)

...Institutions of higher learning are simply masculine in nature and this is accompanied by a cold, offstandish, even at times, harsh culture of engagement. This is reflected also in even the architecture, the way spaces are organized where you walk in certain passages and your body literally quivers; how academic mothers and leaders are perceived, the integration of 'others' e.g. children into the institution of higher learning, are simply not 'seen' (Respondent 16).
\end{abstract}

\subsection{Strategies used by women to support themselves in their leadership positions}

The themes that emerged from the responses related to support from colleagues, friends and even some referred to their personal convictions that respondents used to support them in their respective roles. These sentiments concur with the literature review on women in academia. Many of the challenges experienced by women and in particular in this study have their origins in the patriarchal notion of the private/public divide and stereotypic notions of 'male' and 'female' work 
and roles. These traditional notions of 'man's work' being in the public sphere (characterized by dealings with matters of the mind), and 'woman's work' in the private sphere (characterized by dealings with emotional matters), continue to have salience in contemporary societies (Aisenberg \& Harrington, 1988; Madsen et al, 2012; Subotzky, 2001). The notion of gendered governance refers to the way in which men and women learn what is valued as well as participation in decision making. Such learning frequently determines their roles and identities in the social order and their perceived entitlements as members of a given society.

Respondents were candid about responding to this question and varied responses were received as is evident from the excerpts below.

\subsection{Reflections on the support by close friends, family members and personal convictions}

Women are confronted with ' juggling' on a daily basis which often have consequences which are described by (Bagilhole, 2000; de la Rey, 1999; Subotzky, 2001) and find ways to cope with the multiple roles.

These challenges are experienced by the following quotations from respondents:

... Role models at work as well as social (family, friends) - talking to, discussing. I also use my Faith; Biblical values; own judgment in distinguishing right from wrong (Respondent 15)

...l also try and let the administrative staff see me as a women though referring to my own role as shopper, budgetter at home, etc, so that I Ido not seem totally alien and 'up there'. Most of my administrative staff are female which can set up contest (Respondent 10).

Juggling may result in feelings of insecurity and a slower progression on the career ladder because when women join the work force, they do not always relinquish their home responsibilities. For some women, work outside the home is often not experienced as a liberating experience, but rather as an added burden (Welch, 1990).

These comments indicate what the feminist standpoint theorists refer to as 'invisibility' when women's work is regarded as invisible and insignificant in the. The value of using the feminist standpoint theory for the interpretation of the data is that it provided a space for women's voices to be heard. It also provides an opportunity for women's experiences and opinions to be raised and documented (Harding, 2004; Hennessy, 1995).

Women also indicate that finding other strategies to cope in the androcentric environment assist them in their positions as is illustrated by the quotations below:

.... Being creative, supportive, persuasive, motivated to get the job done (Respondent 13) silence, avoidance of conflict and politics, keeping busy with constructive things like publications, meetings with students, motivating students and working on KPAs in order to show minimal delivery (Respondent 12).

Also, as per the literature (Crosby 2001), it is argued that the emphasis on inter-role conflict serves to maintain the status quo, where men are expected to remain on the peripheries of homemaking activities (Crosby, 1991; Hornsby et al., 2012; Hewlett \& Buck Luce, 2005; Madsen et al, 2012).

The following respondent agrees with the previous scholars' on the 'double load' that women in academia experience:
... I have learnt to take time out and I do not take my problems home in a way that impacts on my life outside of work. I essentially do not sweat the little things. However, I do not have a group of men or women at my level that I can turn to but I have friends outside and inside of academia that I just chat to or hang out with. I still maintain a publication output and supervise doctoral and master students and that helps me deal with the operational challenges of my job - I cannot only be a manager as I am afraid of dumbing down and I am very clear that I need to make a contribution both as an academic and a leader in higher education. I also write op-ed pieces to clear my head and rid myself of frustrations that I am experiencing in South Africa or in Higher Education in South Africa (Respondent 11)
... Home and family, walking across the campus, visiting a like-minded colleague. (Respondent 10).

Welch (1990) alludes to these concepts and sentiments when he states that women often feel insecure as they do not often release their socialized identities in the workplace.

... I ensure that I am always well prepared and perform optimally so that my ability and performance are not questioned. I am confident of the value I add to the organization (Respondent 1). 


\title{
4.8 Support by mentors and colleagues
}

Women feel that they require the support of mentors and colleagues in the positions they hold in order to be successful. This is echoed in the excerpts from the responses, below:

\begin{abstract}
.. For me, being involved in a larger university-wide project has been very supportive and energising. I have derived a lot of support from this loose collective of people from across faculties, and our sharing of challenges related to our roles has been very valuable (Respondent 7 )

.... I use the services of a coach to ensure that I am empowered to identify strategies that best meet my leadership needs (Respondent 2)
\end{abstract}

These overt and conscious strategies may be required by women by women because 'Juggling' and given that women still bear the primary responsibility for both the care of children and the management of the household, the intensity and the number of roles for which women are responsible often contribute to more strain on mothers than on fathers (Acker, 1990; Hewlett \& Buck Luce, 2005)

For some women, work outside the home is often not experienced as a liberating experience, but rather as an added burden (Welch, 1990). When one adds the dimension of gender to time, that in a patriarchal society, spare time is acquired for one gender (for men) by converting the whole lifetime of the women into labour because of juggling.

\section{Conclusions}

The findings highlight the resilience required by women in leadership positions in Higher Education. The challenge for women in leadership positions in Higher Education remains within the narrow margins of the administrative (senior) ranks in Higher Education. Several barriers were highlighted that explain the dearth of women in leadership positions and these include institutional cultures that appear to be a change -resistant component that promotes an environment dominated by male values and for the most part justifies women's self -exclusion form leadership positions.

The feminist standpoint theory, as a conceptual framework provided a 'space' where the respondents' 'voices' could be heard. The examination of the qualitative data does not provide the reasons and this study aimed to provide a 'snapshot' of the reasons behind the numbers that are illustrated in the statistics that indicate the low numbers of women in senior positions in Higher Education.

The findings of the study concur with other scholars that the influx of women in academia has not been accompanied with cultural transformation in the expectations for gender roles. From the findings and discussion the juxtaposition of the perceived barriers and the reported support strategies used by the respondents reflect that these women, (who are all in leadership positions in Higher Education), often feel alienated and continue to experience the 'chilly climate' of working in the domain of the 'old boys' club. Thus, the gendered careers of women are exacerbated because there are not enough women in leadership positions within the Higher Education. This lack of critical mass means that it will take many years to grow a pipeline of women leaders. The 'mommy track' and the 'double load' are also is also acknowledged as having impacts on the careers of women. The respondents expressed that they often find support structures outside their workplaces to 'centre' themselves for and in the positions they occupy.

\section{Recommendations: The Way Forward}

Many women in male-dominated environments and careers experience feelings of isolation, rejection and opposition while those who feel institutionally and socially supported are more likely to progress faster and succeed (Olaide Oti, 2013). It is thus evident that universities often struggle to create institutional cultures that provide a supportive workplace environment for women (Hornsby et al., 2012). Therefore universities, which have traditionally been sites of research rather than the objects and subjects of research studies, have thus been on the sidelines of any such analytical ventures (Madsen, 2011; Tomas et al, 2010) and must continue to prioritize the debate and analysis of women's positions and make concerted efforts to support and inspire women to take up leadership positions. It is therefore recommended that Higher Education institutions develop strategies to support the provision of networking opportunities and mentors to support women in their leadership positions. Further studies to explore the strategies required to support women in leadership positions in Higher Education. 


\section{Acknowledgements}

I pay tribute and express my gratitude to the respondents whose 'voices' and contributions made this study possible. May they go from strength to strength.

I also acknowledge Prof Micheal van Wyk for unselfishly giving of his time in this process.

\section{References}

Acker, S. 1990. Women in universities. Unpublished paper to AUT Women's Group, University of Bristol.

Aisenberg, N. \& Harrington, M. 1988. Women of the academe: Outsiders in the sacred grove. Amherst: Sage Publications.

Bagilhole, B. 2000. Too little too late? An assessment of national initiatives for women academics in the British university system. Higher Education in Europe, 25 (2): 139 - 146.

Becher, T. (1989). Academic tribes and territories. Intellectual inquiry and the cultures of disciplines. Milton Keys: The Society for Research into Higher Education.

Castillo Baltodano, J., Carlson, S., Witcher Jackson, L. \& Mitchell, W. 2012. Networking to Leadership in Higher Education: National and state based Programs and Networks for Developing Women. Advances in Developing Human Resources 14 (1): 62 - 78.

Chant, S. \& Gutmann, M. 2002.'Men-streaming' gender? Questions for gender development policy in the twenty-first century. Progress in Development Studies,2 (4), 269 -283.

Christman, D. \& McClellan, R. 2008. 'Living on Barbed Wire'- Resilient Women Administrators in Educational Leadership Programs. Educational Administration Quarterly, 44 (1): 3-29.

Collins, P. 1997. Comment on Hekman's 'Truth and method: Femist Standppoint Theory Revisted' where's the power? JSOR: Signs 22(2 Winter 1997): 375-381.

Crosby, F. 1991. The unexpected advantages of balancing career and home forwomen and their families: Juggling. New York: The Free Press.

Evans, M. 1996. Ivory Towers: life in the mind in Morley, L. \& Walsh, V. 1996. Feminist Academics: creative Agents for Change. London: Taylor \& Francis.

Denzin, N. \& Lincoln, Y. 1998. Collecting and interpreting qualitative materials. California: Sage Publications.

Evetts, J. 1994. Woman \& career: Themes and issues in advanced industrial societies. England: Longman Group UK Limited.

Halsey, A. 1992. Decline of donnish dominion: The British Professions in the Twentieth Century. Oxford: Clarendon Press.

Harding, S. 1991. Whose science? Whose knowledge? Thinking from women's lives. Ithaca, NY: Cornell University Press.

Harding, S. 2004. The Feminst Standpoint Reader: Intellectual and Political Contoversies. Routledge: New York.

Harper, E., Baldwin, R., Gansneder.B. \& Chronister, J. 2001. Full-time women faculty off the tenure track: profile and practice. The review of Higher Education, 24 (3): 237 - 257.

Hartsock, N. 1998. The feminist standpoint revisited and other essays. Colorado: Westview Press.

Hendricks, C. 1993. Gender revisited. Agenda, 19: 86-87.

Hennessy, R. 1995. Women's lives/feminist knowledge: Feminist standpoint as ideology critique. http://www.cas.ilstu.edu/english Istrickland/495/henness1.html

Henry, M. 1990. Voices of academic women on feminine gender scripts. British Journal of Sociology of Education, 11 (2): 121 - 136.

Hewlett, S. \& Buck Luce, C. 2005. Off-Ramps and On-Ramps. Keeping Talented Women on the road to Success. Harvard Business Review, March: 43-54.

Hochschild, A. 1989. The second shift. Working parents and the revolution at home. New York: Viking.

Hornsby, E., Morrow-Jones, H. \& Ballam, D. 2012. Leadership Development for Faculty Women at Ohio State University: The President and Provost's Leadership Institute. Advances in Developing Human Resources, 2012 14: 96-112.

Loder, T. 2005. Women Administrators Negotiate Work-family Conflicts in Changing times: An intergenerational Perspective. Education Administration Quarterly 41: 741- 776.

Madsen, S. 2011. Women and Leadership in Higher Education: Current Realities, Challenges and Future Directions. Advances in Developing Human Resources 14 (1): 131 - 139.

Madsen, S., Longman, K. \& Daniels, J. 2012. Women's Leadership Development in Higher Education: Conclusion and Implications for HRD. Advances in Developing Human Resources 14 (1): 3-28.

Morley, L., Unterhalter, E. \& Gold, A. (2001). Managing gendered change in Commonwealth Higher education. Paper presented at conference on Globalisation and Higher Education: Views from the South, Cape Town.

Nicholson, L. 2013. Feminism/Postmodernism. New York: Routledge.

Olaide Oti, A. 2013. Social Predictors of Female Academics' Career Growth and leadership Positions in South-western Nigerian Universities. Sage Open 2013 3: 1-12.

Park, S. (1996). Research, teaching and service: Why shouldn't women's work count? Journal of Higher Education, 68 (1): 46 - 84.

Peacock, K. 1993). South African Universities: race and gender in employment patterns. Johannesburg: Union of Democratic University Staff Associations.

Potts, L. 2000. Interpreting the Employment Equity in the university setting: The case of the University of the Western Cape. Unpublished M.Phil.diss. Faculty of Education, University of the Western Cape. 
Reay, D. 1996a. Dealing with differences. Feminism and Psychology, 6: 443 -456.

Reay, D. 1996b. Insider perspectives or stealing the words out of women's mouths: Interpretation in the research process. Feminist Review, 53: $57-73$

Ratcliff, C.2006. Feminist Standpoint Theory. Encyclopedia of Gender andInformation: 335-340.

Reinharz, S. 1992. Feminist methods in social research. New York: Oxford University Press.

Subotzky, G. 2001. Addressing equity and excellence in relation to employment: What prospects for transformative change in South Africa? Equity \& Excellence in Education, 34 (3): 56 - 69.

Tomas, M., Manuel Lavie, J., del Mar Duran, M and Guillamon, C. 2010. Women in Academic Administration at the University. Educational Management Administration \& Leadership, 38(4):487-498.

Walker, M. 1998. Academic identities: women on a South African landscape. British Journal of Sociology of Education, 19 (3): 334 - 345. Welch, L. 1990. Women in Higher Education: Changes and challenges. New York: Praeger Publishers.

West, J. \& Lyon, K. 1995. The trouble with equal opportunities: The case of women academics. Gender \& Education, 7 (1): 51 - 69.

Wilson, R. 1999. An MIT professor's suspicion of bias leads to a new movement for academic women. Chronicle of Higher Education, 46 (15): 16- 19. 